\title{
Towards a Typology of Semiotic Criticism in Italy
}

\author{
Maria Corti
}

Over the last twenty years Italy has played an active part in a great process of reflection and theorization that has involved literary criticism in both Europe and America. An observer may be pardoned if from time to time he has been led to believe that criticism is an inexorable, never ending methodological adventure. The reason for this is no mystery: there was indeed a degree of inevitability. In our time knowledge in all its forms looks to technology and attempts the interdisciplinary. Literary criticism, too, has taken unto itself ideas and models that derive from such disciplines as linguistics, information theory, semiotics, and psychoanalysis, to say nothing of philosophy and mathematical logic (the theory of possible worlds). In 1970 Cesare Segre and I edited a collective work entitled I metodi attuali della critica in Italia: it provides a clear overview of different critical approaches-sociological, symbolist, stylistic, formalist, structuralist, semiotic, and psychoanalytical as they were followed in Italy down to the year in question, 1970. Leafing through its pages today allows one to evaluate just how much ground Italian criticism has covered from that date to this. It also serves to show that there are certain characteristics that are specific to our culture, ones which mark it off from the other cultures of Europe, particularly from the French.

On the one hand there exists a well-established tradition of philological and stylistic studies; and on the other, the fact that literary history has been regarded as the history of genres and of literary institutions has made abstract formalization impossible for us: indeed it has let us conduct investigations whose roots lie deep in the text itself and in the culture that brought it into being. From this point of view, literary criticism in Italy, and the Pavia School in particular, is far closer to the researches of the School of Tartu and of Moscow or to certain sectors of German criticism than it is to anything French.

A rapid synthesis of the critical approaches of the immediate past, which constitute the humus for those of the present, would of necessity include 1) stylistic criticism whose forerunners are Spitzer's Stilkritique and Bally's stylistics of the language. In Italy particular stress has been laid on literary language, on its registers, its écritures, on the typology of literary language. 2) Considerable importance has also been given to the work seen as product: thus began criticism of variants as codified in a number of celebrated articles by Gianfranco Contini. Distant in time though they are (they date from 1947 
and 1951), they can be regarded as the archetypes of variant criticism in Italy, and of structuralist criticism as well. Indeed, Contini was already speaking of spostamenti nel sisterna ("shifts within the system"). 3) The third forerunner of present-day criticism is the linguistic and stylistic research of historians of the Italian language, who have always seen the problems that the text poses within a complex framework of innovation and rejection, and in relation to the literary language of the tradition.

Structuralist criticism took root in this terrain and semiotic criticism followed it. As for structuralist literary criticism in Italy, a good starting point is an investigation carried out by Cesare Segre in Strutturalismo e critica. Those who contributed were, in alphabetical order, Giulio Argan, D'Arco Silvio Avalle, Roland Barthes, Mario Bortolotto, myself, Hugo Friedrich, Werner Hofman, Claude Lévi-Strauss, Samuel R. Levin, Enzo Paci, Aurelio Roncaglia, Luigi Rosiello, Jean Starobinski and Vittorio Strada. It takes us back to a moment (1965) when what was being discussed was whether structuralist methods could validly be applied to literary criticism.

In historical terms, structuralist criticism presupposed a certain conception of the literary text: it concentrated on structural coherence and on the interactions of formal functions at the various levels on which the text achieved realization.

From 1968 to 1970 the semiotic point of view gradually gained ground, and even opened up whole new areas for structuralist research. The notion of the functionality of the literary text was now flanked by another notion: one spoke of its sign function, or rather, to use Umberto Eco's 1975 definition, of its sign superfunction.

Our aim here is to offer a necessarily brief typology of the research that has been carried out over recent years in Italy in the field of semiotic literary criticism. We shall deal with the notions involved and with the corresponding terminology as it relates to the objects under investigation. The two most important of these notions have been that of culture and that of text. Our discourse will be at once metacritical and linguistic. Unfortunately, there exist in Italy, and not in Italy alone, intellectuals whose overriding mental ambition is the pursuit of technical terms for their own sake. They find the siren of technical terminology so enchanting that they are prepared to sacrifice the poetical text itself to the terminology that should serve to elucidate it. Bateson in the United States suggested long ago that the minds of such intellectuals need a kind of ecology, a mental spring cleaning. This is something that needs to be said, and having said it, we can move on to describe a preliminary group of notions, together with the technical terms that correspond to them and the scholars who have made use of them.

Our prime object of analysis is the notion of culture seen as a whole. In Italy, where we are indebted to Russian semiotics (and to the Tartu School in particular), culture has taken on a rather special connotation, one that is both technically and semantically illuminating: we now commonly refer 
to the textuality of culture, and the lexeme textuality with its derivation syntagm textuality of culure owe their particular fortune to an influential book, J. Lotman and B. Uspenskij's Tipologia della cultura, which appeared in 1975 in the "Studi Bompiani" under the general editorship of Umberto Eco. The notion of the textuality of culture underlines the fact that a text is not just a reality whose organization, in its written/oral variants, is effected by means of verbal signs. It is any expression whose construction and organization is effected by making use of a system of signs. Thus a painting is a text, and so is a procession or a political rally. In other words, a text is any sign manifestation whatsoever irrespective of whether it is ritualized or not. We shall soon sec that the notion of textuality is no less fruitful when applied to the historical-critical and linguistic notion of "semantic field."

Clearly what is being brought into focus is not just the hierarchization of the textual levels within a given culture, and the coexistence of levels that are alternatively conservative and innovative, closed and open, fixed and mobile: we are also concerned with the well-defined cultural model that each era generates. It is a model that can be isolated from the all-cmbracing textuality of culture, even though it is highly probable that, at any given moment, those who act as its depositories and those who participate in it are substantially aware of its existence. In this area of considerations we are once again indebted to Lotman for the technical term self-model. The strongly marked modellizing tendency of culture may favour the creation within itself of a self-model. This self-model is a kind of "anticipated regularization" of the dominant culture. A good example is the tripartite model (oratores, laboratores, and aratores) that we find in the Middle Ages. It is a selfmodel, one that is generated by the socially dominant ruling class. It acts as a mechanism for the production of hierarchies and rules. Relations between a culture and its self-model are often highly complex, and may even be dramatic. The Middle Ages themselves provide us with an extreme example: from the margins of culture (from the world of the clerici vagantes, of the minstrels, etc.) an opposition model comes into being, indeed an anti-model. The term as such is not used by Lotman and Uspenskij, I believe, but in the recent past I have found myself obliged to have recourse to it on a number of occasions. Any number of anti-models or opposition models may be found in the Carmina Burana; and a most significant medieval text, Solomon et Marculfus, embodies both model and anti-model in the shape of Solomon the king and Marcolph the peasant. Their opposition throughout the exchanges of a lengthy dialogue is systematic and, when examined semiotically, it can be transformed into a message of far greater intensity. The lexemes textuality. self-model, anti-model, seen in the light of real problems like this, stand up to the most stringent examination and are found to be neither gratuitous nor optional. They work well and are an excellent vehicle for new information. Their pertinence as linguistic instruments lies in the mental organization they represent. 
Theoretical reflection on the mechanisms of culture has led semiotic criticism in Italy to innovate independently in its terminology. Terms like fields of forces and shifting semantic fields are closely linked to these perceptions. Inside the dynamic mechanism of culture the distinctive traits of an age stand in direct opposition to those of its earlier phases. Culture attempts to transform the latter, to render them harmless and to absorb them. Such dynamism produces an intermediate phase midway between the old and the new, a phase of interaction and of conflict between conservative, centripetal forces and others that are innovative and centrifugal. Fields of force are the outcome: and it is within a dynamism of this kind that neo-realism and the neo-avantgarde exist and have their being, and so, in a far more serious dimension, did the great philosophical and scientific innovations of the thirteenth century.

The notion of field of forces is necessarily linked to that of mobile semantic fields. This finds its basis in a syntagm, "semantic field," proper to linguistics, where it indicates a type of semantic relationship among a certain number of monemes. In the linguistic field itself, the notion of semantic field may well take on quite different characterizations, as research over the past forty years has shown. Recently Lyons has talked of relationships of hyponymy and of hyperonymy. Pertinent to our discourse is the fact that Trier, as long ago as 1934, when dealing with lexical fields and conceptual fields with regard to philosophical language, pointed out not just the way in which certain lexemes disappear as other new ones are created to replace them: he also showed that sense relationships between one lexeme and its neighbouring lexemes change over time within the language. Lyons sets out from here, and arrives at what is unquestionably a stricter view of the relationship between the conceptual field and the semantic field. His point of view is, however, that of the linguist, and this leads him to concentrate exclusively on changes seen diachronically.

I myself have made use of the term "mobile semantic field" in an effort to bring to the fore an essentially synchronic phenomenon. It can happen that on one specific level of culture the lexemes of a given semantic field correlate in a certain manner, while on another level, because of the influence of specific theories or cultural interests, their correlation will be quite different. This mobility in the semantic field is due to the fact that at a certain level only polysemy is produced in several of the lexemes in play. For example, in the thirtecnth century nobilitas on one level means nobilitas generis, and is correlated with, or opposed to, nobilitas animi; on another level, that of the new lay speculation in philosophy, nobilitas is like Aristotelian sofia, and means contemplative capacity. In this new sense, it draws the lexeme felicitas magnet-like into its own semantic ficld, and reproduces thereby the Aristotelian pairing sofia-makaria. Obviously mobility of this kind in the semantic field, by the very fact of its being synchronic, is as pertinent to literary criticism as it is to linguistics. It makes it much easier to insert a text, on the basis of its lexemes, into its rightful place in the overall textuality of the culture of its time. 
Again, it is in the light of the notion of intertextuality that the relationships between interdiscursivity and intertextucility can be further illuminated. Interdiscursive is a neologism introduced by Segre, who modelled it on Bachtin's pluridiscursive. Segre uses it to stand for "those relationships which any text, whether oral or written, maintains with all the utterances (or discourses) that are recorded in the corresponding culture: they are arranged ideologically and in terms of registers and levels as well." Here is an example: when Dante, in the Convivio, Book IV, chapter XVII, paragraph 8, writes "Felicitade c secondo virtude in vita perfetta," it is certain that he is not referring directly to the first book of the Nicomachean Ethics. The saying he quotes had long since become part of the general cultural code: it was, by other words, of its very nature interdiscursive. Scgre's new term acts primarily as a convenient label, and it has the advantage of avoiding periphrastic explanation.

The notion of interdiscursivity, as can be seen, may sometimes serve to re-dimension that of intertextuality. There is no need to dwell on this term, for by now it has entered into general use. It should be pointed out though that in the Italian tradition this lexeme has taken on a meaning of its own, one that does not coincide with that conferred upon it by Julia Kristeva. When in 1966 she coined the term interlextualite she made it stand for a transposition from one or more systems of signs to another such system. In Italy, however, the notion of intertextuality has been brought into relation with the investigation of sources, a fact that has in some measure entailed a kind of typology: intertextuality is seen as being direct, indirect, interlocking, internal, regressive, and so on.

The notion of macrosign, developed by Avalle, is another uscful notion that also makes reference to a theory of culture. Avalle applied it to the concept of "motif" as defined in the pioneering work of the Russian scholar, Veselovsky. For Veselovsky, motifs or topoi are units of narrative measure, and are to be found in all literatures. We encounter the motif of the love triangle, that of star-crossed love, that of the persecuted maiden, etc., and they run like strands throughout the literature of all nations, finding their embodiment in single texts thanks to an interplay of combinations that brings into play intertextual constants and textual variants. Avalle goes even further in his Modelli semiologici nella Commedia di Dante: "the narrative macrosign is a complex sign that is broken down into a certain number of "component parts' or 'narrative units' (which here function as 'signifiers'); by means of these a "motif' finds expression (with its value of 'signified')" (20). He breaks the motif down into smaller narrative units than does Veselovsky, and among the examples he gives we find the "hubris-nemesis" motif (crime and punishment), that of the medicval contes d'adulieres, or that of the hero who journeys into lands unknown or forbidden (Alexander, Ulysses), and so one. Today, in the wake of Bachtin, motif analysis has been rendered even more complex in the light of his illuminating considerations of time-space relationships. But this is a subject that cannot be dealt with here. 
In the field of research into, and analysis of, motifs, Italian literary criticism has taken over from M. Popp, a Rumanian folklore specialist, the neologism motiveme, deriving it from an article of his, La poétique du conte populaire ("Semiotica", II, 1970), and transferring it to the area of literature. A motiveme is any unit of a motif that is susceptible of being reproduced at will in terms of a series of variants: it thus represents a point of freedom, an opening, within the narrative structure. We may find it being employed not just in oral transmission, for a writer may make use of it too when his aim is a particular kind of iteration. Calvino, for example, in his play La panchina, emphasizes, with respect to the two short stories (or pseudo-fables) from which it derives, the motif of the obstacle to Marcovaldo's sleeping on the bench. He does this by multiplying the number of antagonists who succeed one another in the square. An author is at liberty to do this to a plot without in any way modifying it, because the motif unit (meeting with an obstacle) can be extended and reproduced at will. It is a free point of the narrative structure.

Everything that we have said so far, rapid though our survey has been, serves to highlight two specific characteristics of one sector of contemporary literary criticism in Italy. They do indeed mark it off from French criticism, for example. Literary criticism in Italy is linked to history very closely indeed. It is innovative potential one searches for, alive to the kind of diachronic and synchronic relationships that involve history, literature and language. That this is a typology is obvious enough, but it is a typology that is anything but abstract. The second significant aspect of specifically Italian criticism concerns its actants. All the scholars we have been talking of come from disciplines like Romance Philology and History of the Italian Language, which are concerned with the investigation of the processes in terms of which texts and contexts interact.

Let us go on to the notion of text. Literary criticism in Italy had moved over this terrain long before so-called text-criticism. Philology and textual criticism had already been provided with efficient models on an ontological and pragmatic level, and they worked well; furthermore, stylistic criticism of the fifties and sixties afforded excellent examples of an organic approach to the artistic text. Negative confirmation can be found in the borrowings and suggestions derived from linguistics. They come by turns from Saussure, historical linguistics, from structuralism, Chomsky, and Austin. The influence of text-linguistics is slight and only recent.

To a general theory of the text must be related the notions expressed by the terms avantext and macrotext. By avantext and avantextual (or pre-textual) phase is designated that process of generation and development of the artistic text that lies behind its textual execution in the strict sense, in other words the dynamics of invention, a problem that is very much alive in present-day Italian culture. In 1983 no less than three meetings were dedicated to it, the most important of them proving to be an international meeting, organized by the 
Palazzo Grassi Foundation in Venice, on the topic Gli statuti dell'invenzione.

The problem of invention leads to the notion of avantext when the process of invention and its partial manifestations, the signals it sends, are studied in the context of the function of the text and of its construction. It is ultimately a process that Edgar Allen Poe illustrated so well in The Philosophy of Composition.

The notion of macrotext, investigated by me, and the term I coined to designate $i t$, have since become current. A macrotext is a semiotic unit broader than a single text. The term applies to a collection of texts in poetry or prose whose unity of pattern is such that it presents the transentential aspects proper to any single text. In other words, the single texts of the collection are microstructures arranged within a macrostructure; hence the functional and informative character of the collection. Such functionality and the possibility of supplementing "information" is brought about by at least one of the following two conditions: 1) there exists a common pattern combining thematic and/or formal elements which constitutes the unity of the macrotext; 2) there is a veritable progression in the discourse so that each of the texts can occupy only the place assigned to it. The second condition presupposes the first, but the opposite is not the case. A classical example is Petrarch's Canzoniere, while a modern example might be the first series of Calvino's Marcovaldo stories, though not the second.

Let us return to the isolated literary text. Umberto Eco is responsible for the expression (or label) opera aperta. He first employed it in 1962 and subsequently carried out a more thorough-going investigation in his Lector in fabula of 1982. Why exactly do we describe a work as "open"? When the reader (the addressee) cooperates with the work his cooperation is an attempt at interpretation: but the result may well be a number of quite different readings, readings that may or may not have been predetermined by the author (or addressor). What aids and abets this process is the extremely high degree of information and the polyvalence that subtends any great work. This high degree of information is the hallmark of the artistic text, so much so that Umberto Eco has spoken of the sign "superfunction" of the work of art; from this derives a coinage of my own, hypersign, which aims to show how it happens that the overall meaning of a text can be superdetermined over and above the sum of the verbal signs that make it up.

Italian semiologists on occasion transfer from linguistics to the theory of literature and the literary text, notions or terms to which they attribute a new meaning. A good example of the first kind, a borrowing from linguistics that has been found helpful for literary theory, is the notion of diasystem. In linguistics, diasystem is a notion which with its correspective term serves to designate the over-all system to which two cognate systems stand related; it can also mean a compromise when two systems are in contact. From this the Italian semiotician, Cesare Segre, has derived the syntagm stylistic diasystem, and used it to designate the kind of linguistic mixing we find in 
medieval text transcription. Such a blending is the result of two coexisting and complementary sets of readings, one of which is to be attributed to the author's own system, while the other is that of the scribe. The chansons de geste, which were constantly being re-elaborated, constitute an extreme example.

Let us now look at an example of linguistic terminology whose transference has involved a marked semantic shift. In my book Principi della comunicazione letteraria of 1976 (published in English by Indiana UP in 1978 and entitled An Introduction to Literary Semiotics) I borrowed from Hjelmslev the syntagms content form and expression form, although I completely changed their meaning. It was not to the code, or to the language, that I related them but to the message, that is, to the text itself. If the word "form," like the word "discourse," lends itself to an accumulation of polyvalence, this is because language lacks synonyms that might prove appropriate. It has now become common practice in Italy to use "content form" when one wishes to indicate the dynamic relationship through which a text contrives to reconcile the levels of its content (thematic, symbolic and ideological), and the way in which it organizes them into a unity whose overall determination in the text is the result of the norms to which it owes its construction. On the other hand, "expression form" refers to the structural unity of the text's formal levels (which are phono-timbric, rhythmical, syntactical, etc.). The text's invariant factor is the relationship between these two forms. A general observation would seem to be in order: the new function of certain syntagms in critical language, and of certain lexemes as well, is the outcome of their semantic interdependence. I am thinking of the terms fabula, plot, discourse as they are used by Segre in his narratological essays. Not one of these words is new, but all three of them are renewed semantically in the reciprocal relationship they take on within a specific theory of narrative. This is an extremely interesting aspect of the whole question of how a certain kind of criticism makes use of language. Narratology, for example, has its own distinctive, consistent language; and, to return to the past, one of the greatest figures in the field of Italian philology, Gianfranco Contini, forged his own language too. What we are saying is that when a discipline arms itself with new methods of investigation, or when it effects any kind of breakthrough in theory or practice (and this is what semiotic criticism has done), one finds a corresponding tendency to innovate at the lexical and semantic level. Over and above the obvious aspect of the matter, it is a fact that new ideas and new applications stand in need of new terms that will provide them with a linguistic passport and enable them to communicate. What it shows is a broadening of the cultural areas with which the discipline under discussion is coming into contact. We are faced, in other words, with stimulating examples of inter-disciplinary cross-fertilization (a meeting of literary theory, semiotics, linguistics, philology, and so forth).

What we might call the Venetian School occupies a place apart within the 
framework of Italian semiotic criticism. It has grown up around the figure of Stefano Agosti, whose field is French literature and whose relationship with French semiotic thinking is unique. In Agosti's writings the syntagm latoro del testo is endowed with a rather special technical sense. It serves to define a particular textual operation, language at work upon language. And here we might remember the Russian poet Osip Mandelstam, who, in his remarkable Discourse on Dante, had already referred to the text as a formal mechanism for the generation of meaning.

If we are to understand Agosti's discourse and that of his followers, a preliminary postulate is imperative. There exists inside language a fundamental watershed: on one side we have so-called "mimetic-metaphorical" language, which corresponds to discourse of various kinds, communicative, pragmatic, technical, philosophical, sporting, etc; on the other, we find poetical language. It is here in poetical language that elaboration of the text, il lavoro del testo, is effected; it is here that meaning is produced. For Agosti there are three main ways in which a text is able to produce meaning: there are formal messages (supersegmental, trans-segmental, phono-timbric associations); there are informal messages (and the neologism here has a technical value; for Agosti, "informal messages" are what French critics call the dissémination de la lettre; in other words, the associations that are produced at a subsequental level: anagrams, the subterranean movements of écritures, seen as constituents of the text's real elaboration). Lastly, there is a third kind of production of meaning that is due to rhetorical messages that are the result of semantic contamination (and here we might well link Agosti to Ivan Fonagy, to the Fonagy of Redondances expressives dans l'aure poétique in particular).

So far, we have referred to two groups of researchers in the field of literary semiotics. One of them owes allegiance in a certain sense to the socalled School of Pavia (Cesare Segre, myself, and our collaborators), to the School of Bologna centred on Umberto Eco, and to the Turin School (Silvio Avalle, Gianluigi Beccaria and their pupils); the other group is made up of the Venetians. For while the Venetians refer to French models, to Derrida, Lacan and the Paris semiologists, the others are far more diversified in terms of the basic problems they deal with (the relationships that exist between society and culture, text and culture, exactly how addresser, text and addressee relate, and so on). It is a group whose antecedents should be sought not only in the indigenous ltalian textual tradition in both its branches, philological-stylistic and historical, but in Russian and American semiotics as well.

This is a rapid bird's-eye view of the geography of Italian literary semiotics in the eighties, and I am well aware of the fact. Before concluding It, though, I should like to glance at the terrain cultivated by a number of Italian researchers in the field of English literature. They form a close-knit group, and are easily recognizable because of the way they analyze English poetical and theatrical texts. The investigation of theatre in semiotic terms in Italy is primarily due to them. What especially attracts them is the metaphorical ap- 
plication of notions derived from the linguistics of Chomsky (deep structure, transformation, etc.) and from text-linguistics (deixis, etc.). They have thoroughly investigated the way in which the text as written relates to the text that is put on stage, the text the audience hears in the theatre. The problems posed by theatrical performance they have made their own. Among those who have worked in this field, mention must be made of Marcello Pagnini, Alessandro Serpieri, Romana Rutelli. And we should add the poet of Hungarian origin, Tomaso Kemeny.

The time has come to conclude. The world of literary criticism in Italy is a highly articulated one; this is reflected on the linguistic level as well. And things are still on the move. Literary criticism, when compared to other disciplines, is in continual communication with the objects of its own investigation, to the point that in Italy it is not uncommon to find that a certain intellectual is creative artist and literary critic at one and the same time. I cannot deal with other aspects of semiotic investigation in contemporary Italy, for example with the whole question of the way a text relates to its public, of how it is deciphered and received, or the way literary genres are linked to society. We are now faced with a bibliography that is immense, but Borges reminds us that any choice involves of necessity a rejection. I have endeavoured to concentrate on those fields of research where semiotic criticism in Italy can lay claim to some degree of originality when it is compared with that of other countries, fields in which its specific character is best revealed.

Let me conclude with a reflection of Borges and Bioy Casares (from The Chronicles of Bustos Dominica): "Statistics," they tell us, "and all work that is merely descriptive, merely informative, always presuppose a splendid and probably crazy belief that the future as it opens before us will provide men who resemble us, but who will be more clear-minded than we are, men who will derive from the data we leave them an astonishing conclusion, an abstraction that will astound." For the present all we can say is that scientific methods applied to the literary world form part of a sublime entertainment "where the aim is to discover the rules, despite the fact that the rules are forever changing and that their discovery will forever be impossible." But this surely can be applied equally well to all that happens to us in the ordinary course of our lives.

Universita di Pavia 